\title{
Thermal Decomposition of Three Types of Copper Clad Laminates Considering the Influence of an Iron-clay Catalyst in the Production of Pollutants
}

Juan A. Conesa ${ }^{* 1}$, Nuria Ortuño ${ }^{1}$, Amelia Zielinska ${ }^{2}$

${ }^{1}$ Department of Chemical Engineering, University of Alicante, P.O. Box 99, 03080 Alicante, Spain

${ }^{2}$ Faculty of Environmental Engineering, Wroclaw University of Technology, Wybrzeże Wyspianskiego 27, 50-379 Wroclaw, Poland,

*Corresponding author:

E-mail: ja.conesa@ua.es

\section{Abstract}

Metal recovering through decomposition in the presence of steam of different wastes has been demonstrated to be an effective method. In the present work, three different types of copper clad laminates (FR4, CEM3 and ROGERS) were subjected to high temperature decomposition, analyzing their performance. Firstly, the samples were analyzed by thermogravimetry, both in the absence and in the presence of oxygen in the atmosphere; FR4 and CEM3 showed a very strong interaction with oxygen, in contrast to ROGERS. Secondly, the laminates underwent oxidative pyrolysis in the presence of steam at $900{ }^{\circ} \mathrm{C}$ in a horizontal laboratory furnace; the experiments ${ }^{\circ}$ were carried out in the presence and in the absence of an iron-clay catalyst, in order to evaluate its effect on the production of pollutants. Analyses of the produced gas and semivolatile species are shown, including polycyclic aromatic hydrocarbons (PAHs), bromophenols (BrPhs) and brominated dioxins and furans (PBDD/Fs). The gaseous emissions are almost limited to methane, hexane, toluene and xylene, and the production of PAHs and other semivolatile compounds is considerably reduced with the use of the iron-clay catalyst. The emissions of $\mathrm{BrPhs}$ and $\mathrm{PBDD} / \mathrm{Fs}$ are also very limited. Comparing among the behavior of the three types of laminates, the emission of brominated compounds is much lower in the gasification of ROGERS, compared to FR4 and CEM3.

Keywords: copper clad laminates, printed circuit boards, dioxin, iron-clay catalyst, thermogravimetry. 


\section{Introduction}

Nowadays a rapid technological development is observed in all kinds of sectors. For this purpose, engineers design composite materials which provide superior quality and long life span. The features of these materials contribute to many applications: electrical and electronic, defense and aerospace, automotive industries, ... Some of the most commonly used are laminates based on reinforcement of glass fiber, such as FR-4, CEM-3 and ROGERS4003 [1].

FR-4 are mainly composed of glass fiber combined with epoxy resin and with outer layers of copper, and are mainly used as a base of printed circuit boards in all types of electrical and electronic equipment, especially in mobile phones [2]. CEM-3, which are very similar to the most commonly used FR-4 ones, consist of a core of vitreous felt (non-woven glass fiber) with an outer layer of woven glass impregnated with epoxy resin, and coated copper on the base plates [3]. However, the amount of brominated epoxy resins (BERs) is lower compared to FR-4. The structure and composition of ROGERS4003 are also similar to FR-4, but consist of a woven glass reinforced hydrocarbon resin with ceramic filler, without brominated flame retardants (BFRs). Worldwide, there is a huge generation of scrap laminates from obsolete and discarded equipment, which are mainly landfilled, with the increasing problems associated to this practice [1]. Additionally, due to its heterogeneous structure and the presence of BFRs, waste printed circuit boards are problematic to recycle. Consequently, appropriate treatment approaches are being sought for these types of materials.

The process of thermal decomposition of laminates composed of multilayer plastics, resins and metals has been studied with the objective of extracting the metals without melting the system $[4,5]$. Decomposition in the presence of steam enables almost complete elimination of char from metals/inorganic structure and reduction (by catalytic conversion) of condensing oils and tars content in the product gas. PVC cables have been studied in this sense, presenting a good recovery of copper through decomposition of plastics at high temperature [6].

Currently, other methods to transform e-waste are being considered, but attention is mainly focused on thermal methods, which have been developed with printed circuit boards (PCBs) that mainly consist of FR-4 laminates with TBBPA (tetrabromobisphenol-A) acting as binder and flame-retardant [7-9]. Some researchers conducted conventional combustion process and 
others used pyrolysis for the treatment of waste PCBs [10-15], focusing mainly on the characterization of solid residue and liquid.

Quan et al. [10] investigated the characterization of two products: pyrolytic oil and solid residue after pyrolysis of PCB waste, performed on a fixed bed reactor at $700{ }^{\circ} \mathrm{C}$. De Marco et al. [11] conducted a pyrolysis process in an autoclave at $500{ }^{\circ} \mathrm{C}$ with four different electronic devices. Solid and liquid yields were also determined. They noticed polymer-free metals could be separated and recycled, and the liquids may be used as fuels or chemical source. Guo et al. [12] reported a thermogravimetric analysis and kinetic study on plastic particles of printed circuit boards. A fluidized bed reactor was also used for the pyrolysis of the samples, analyzing gas, liquid and solid residue yields. Hall et al. [13] achieved the separation of the organic, metallic, and glass fiber fractions of PCBs by means of pyrolysis in a fixed bed reactor at $800{ }^{\circ} \mathrm{C}$. When heated, the organic fraction decomposed to form volatile oils and gases, whereas the metal and glass fiber fractions remained in the pyrolyzed residue, and were easy to separate. Vasile et al. [14] carried out runs with PCBs from obsolete computers using combined procedures of thermal and catalytic pyrolysis. Pyrolysis was performed by semi-batch operation at $300-540{ }^{\circ} \mathrm{C}$. Two catalysts were used: $\mathrm{CaCO}_{3} / \mathrm{cracking}$ catalyst or $\mathrm{CaCO}_{3} /$ cracking catalyst/Red Mud in 2.5:1 and 2.5:1:1 weight ratios, respectively. They noticed that catalytic pyrolysis decreased the amount of all heteroatoms $(\mathrm{Br}, \mathrm{Cl}, \mathrm{N}$ and O) in PCB oils. Besides, Guan et al. [15] investigated the co-pyrolysis of PCBs with calciumbasic compounds. The authors noticed that adding various calcium based waste, the copper foil was not corroded and the additive absorbed the $\mathrm{HBr}$ generated during the process.

Other authors focused on the pollutant production during the thermal decomposition of these materials. Tue et al. [16] pointed out the importance of avoiding uncontrolled recycling processes, due to the formation of hazardous dioxin-related compounds. Duan et al. [17] studied the formation of chlorinated and brominated dibenzo-p-dioxins and furans associated with the low temperature thermal processing of scrap printed circuit boards (PCBs). An important formation of brominated dioxins and furans (PBDD/Fs) was found at 250 and 275 ${ }^{\circ} \mathrm{C}$, both under $\mathrm{N}_{2}$ and air atmospheres. Further research was reported by Ortuño et al. [7], who analyzed the pollutant emissions during pyrolysis and combustion of PCBs (without and with metal) at high temperatures: 600 and $850{ }^{\circ} \mathrm{C}$. The extensive research provided information on the generation of halogen gases and hydrogen halides, gases and volatile compounds, semivolatile compounds (including bromophenols and PAHs) and PBDD/Fs.

Nowadays, studies on elimination of e-waste concentrate on decomposition in the presence of steam, which has been used for biomass either without catalyst $[18,19]$ or with various 
kinds of catalyst: Ni catalyst [20], Fe/olivine [21], dolomite [22-24], untreated olivine [22], clay catalyst with precursors $[6,25]$. Based on this knowledge, recycling methodologies of waste electrical and electronic equipment (WEEE) are being developed. Potential technology should aim to obtaining valuable solid residue with metals in its original form, the reduction of tars, oils and volatile compounds and production of a clean gas enriched with hydrogen.

Mońka et al. [26] dealt with the steam decomposition process of RAM memory waste under a steam flow at high temperature $\left(750{ }^{\circ} \mathrm{C}\right.$ for 1 hour, $790{ }^{\circ} \mathrm{C}$ for 20 minutes). The treatment was carried out on solid residue in its original form. The study showed that this process may be considered as a promising technology for WEEE recycling.

Salbidegoitia et al. [27] carried out the pyrolysis of phenolic boards in the presence of LNK-carbonate mixture $\left(\mathrm{Li}_{2} \mathrm{CO}_{3}, \mathrm{Na}_{2} \mathrm{CO}_{3}\right.$ and $\mathrm{K}_{2} \mathrm{CO}_{3}$ plus nickel powder) at different temperatures $\left(550,600\right.$ and $\left.675^{\circ} \mathrm{C}\right)$ to produce clean hydrogen. They observed that the addition of metal powder lead to a decrease of the organic matter content in the solid residue. Moreover, rates of hydrogen formation were accelerated when nickel powder was used.

Zabłocka-Malicka et al. [6] discussed the copper recovery from PVC multi-wire cable waste during thermal decomposition in steam atmosphere. They found that the organic fraction was completely removed from the wires after the treatment. Furthermore, copper was preserved in unmodified form and the rate of copper recovery was close to $100 \%$.

In the present study, three laminates: FR4, CEM3 and ROGERS4003 were analyzed in the thermobalance in order to characterize their thermal decomposition. Then, the samples were subjected to thermal decomposition, without and with iron-clay catalyst. This procedure has been demonstrated to be effective in the recovery of metals, but the pollutant production has not been considered so far. For this purpose, the gases, light hydrocarbons, polycyclic aromatic hydrocarbons (PAHs), brominated phenols (BrPhs) and brominated dioxins and furans (PBDD/Fs) were analyzed, with special attention to examine the influence of the presence of catalyst in the emissions of pollutants.

\section{Materials and methods}

\subsection{Laminates}

Three types of laminates were studied in the present work, FR4, CEM3 and ROGERS4003, supplied by an international company. To homogenize them, the samples were crushed by a vibratory disc mill by Herzog, HSM 100 (Osnabruch, Germany). 
A CHNS analyzer (FlashEA 1112 Series, ThermoFinnigan) was used for elemental analysis, and the oxygen was obtained by difference. Also, the heating values of the samples were measured, using an AC-350 calorimetric bomb from Leco. Table 1 presents these results.

Equally, a semi-quantitative X-Ray fluorescence analysis was also performed using a Philips PW2400 X-ray fluorescence (XRF) Spectrometer. The results are shown in Table 2. In all materials, the main elements found were silica, calcium, aluminum and copper.

In order to obtain information about the content of halogens in FR4, CEM3 and ROGERS4003, EPA Method 5050 [28] was used, analyzing the obtained solutions by ion chromatography (Dionex DX-500). The amount of bromine (Br) was: 5.28, 3.77 and $0.004 \mathrm{wt}$ $\%$, for chlorine $(\mathrm{Cl}): 0.054,0.035$ and, 0.003, and fluorine $(\mathrm{F}): 0.038,0.036$ and 0.010, respectively. As expected, the amount of bromine is much higher in FR4 and CEM3, because of the presence of brominated flame retardants.

\subsection{Catalyst}

Natural alumino-silicate was gained from a small, local deposit in Dzierżoniów County (south-west Poland). Original raw clay was dried at ambient temperature and pulverized below $0.25 \mathrm{~mm}$, and this was used for the formation of wet granules followed by drying and calcination. Preparation procedure was based on the one described by Miao at al. [29]. The clay and precursor powder: iron (III) oxide, Fe2O3, CAS 1309-37-1, pure POCH S.A. Poland (fractions below $0.25 \mathrm{~mm}$ ) were mixed with polyethylene glycol (Carl Roth $\mathrm{GmbH}$, ROTH 600, molar mass: 570-630 g/mol) and distilled water in weight proportions of 22/44/12/22. The mixture was homogenized and granules with 5-6 mm diameter were formed and dried for 24 hours at $105^{\circ} \mathrm{C}$, then heated (in Nabertherm $\mathrm{GmbH} \mathrm{N} 150$ furnace) from ambient temperature to $950^{\circ} \mathrm{C}$ for $9 \mathrm{~h}$, calcined for $3 \mathrm{~h}$ at $950^{\circ} \mathrm{C}$ and cooled down gradually to ambient temperature. Weight losses during drying and calcination were equal to $20 \%$ and $30 \%$. The characterization of iron-clay granules (elemental composition and basic properties of catalyst) was described in the literature [25].

\subsection{Experimental setup}

On the one hand, thermogravimetric runs of samples were carried out on a Mettler Toledo TGA/SDTA851e/SF/1100 Thermal Gravimetric Analyzer. The decomposition temperatures were measured under dynamic conditions in pyrolysis $\left(\mathrm{N}_{2}\right.$ atmosphere) and oxidative pyrolysis (air atmosphere) with a total flow rate of $100 \mathrm{~mL} \mathrm{~min}{ }^{-1}$. Dynamic runs were 
performed at heating rates of 5,10 and $20 \mathrm{~K} \mathrm{~min}^{-1}$ for each atmosphere, from room temperature up to $1173 \mathrm{~K}$. For each run $10 \pm 0.3 \mathrm{mg}$ of sample were used.

Besides, experiments were performed in a moving tubular quartz reactor located inside a horizontal laboratory furnace, described in detail elsewhere [30]. In all runs the temperature of the oven was $900{ }^{\circ} \mathrm{C}$. The carrier gas (nitrogen) flow rate was $500 \mathrm{~mL} / \mathrm{min}$, maintaining a relative humidity of $85 \%$ (details on the system have been previously reported [23]). Before each run started, the reactor was flushed for $0.5 \mathrm{~h}$ with the mix of steam and nitrogen.

Eight runs were conducted: three samples without catalyst and three with iron-clay catalyst, apart from one blank without and with catalyst. The catalyst was placed at the end of the reactor and maintained at the same temperature, $900{ }^{\circ} \mathrm{C}$. The mass of the catalytic bed for each run was about $4.8 \mathrm{~g}$, being the space of quartz tube occupied by catalyst $\sim 8 \mathrm{~cm}$.

In each experiment, fine powdered sample of laminates, in the amount of approximately 1 $\mathrm{g}$, was placed in two quartz boats and fed into the reactor at a constant speed $(1 \mathrm{~mm} / \mathrm{s})$, once the set temperature had been reached. The samples were kept at this high temperature: $80 \mathrm{~min}$ for FR4 and CEM3, and $40 \mathrm{~min}$ for ROGERS4003. This was done in order to keep constant the ratio between the total amount of steam available and the carbon content of the sample, as the $\mathrm{C}$ content of ROGERS laminate halved that of FR4 and CEM3.

Gases were sampled every 10 min into Tedlar $^{\circledR}$ bags (Restek, USA) and analyzed by two gas chromatographs, one equipped with flame ionization detector (FID) for light hydrocarbons between $\mathrm{C} 1$ and $\mathrm{C} 8$, and one with a thermal conductivity detector (TCD) to determine $\mathrm{CO}, \mathrm{CO}_{2}$ and $\mathrm{N}_{2}$.

Volatile products leaving the reactor were trapped into a quartz tube filled with Amberlite ${ }^{\circledR}$ XAD-2 resin (Sigma Aldrich, USA). After each run, the extraction of the resin was performed using a mixture of dichloromethane/acetone, 1:1 vol, as presented in previous work [7]. The analysis of the concentrated extracts was performed with HRGC-MS in the SCAN mode $(\mathrm{m} / \mathrm{z}=35-550)$ with an Agilent HP5-MS $(30 \mathrm{~m} \times 0.25 \mathrm{~mm}$ i.d. $\times 0.25 \mu \mathrm{m})$ capillary column, using the U.S. EPA method 8270D for reference [31]. The results of polycyclic aromatic hydrocarbons (PAHs) and semivolatile compounds were quantified according to this method. Brominated phenols (BrPhs) were specifically analyzed in the SIR mode, and quantified by internal standard calibration, in a similar way to the 16 PAHs. The identification of each isomer was confirmed by checking the ratio between the areas of the primary and the secondary ions.

Furthermore, polybrominated dioxins and furans (PBDD/Fs) were also analyzed by collecting them in $\mathrm{XAD}-2$ resin. ${ }^{13} \mathrm{C}$-labeled internal standards were added to the resin prior to 
extraction, which was performed with two different solvents (dichloromethane and toluene) in subsequent steps [32]. The extracts were concentrated in a rotary evaporator, diluted in nhexane and purified in an automated Power-Prep system with silica, alumina and activated carbon pre-packed columns. Finally, the samples were analyzed in a HRGC-HRMS Micromass Autospec Ultima-NT, equipped with an Agilent DB5-MS (15 m × $0.25 \mathrm{~mm}$ i.d. $\times$ $0.10 \mu \mathrm{m})$ capillary column.

Before the decomposition runs, a control containing no sample was done using the same experimental condition (blank). This procedure was similar to that used in previous work [7], where it can be found the accuracy, precision and recovery of the methods used.

\section{Results and discussion}

\subsection{Thermogravimetry}

Figure 1 presents the decomposition of the three laminates both in pyrolytic (nitrogen) and oxidative pyrolysis conditions (air). The runs were performed at three heating rates for each atmosphere and material. Note that for the mass fraction (y axis), the scale goes from 1 to 0.5 , because the mass loss for these materials is not very high.

Thermal decomposition in inert atmosphere presents two different processes in the case of CEM3 laminate (centered around $275^{\circ} \mathrm{C}$ and $400^{\circ} \mathrm{C}$ ), but only one process for FR4 (centered at around $320^{\circ} \mathrm{C}$ ) and ROGERS (approx. at $400{ }^{\circ} \mathrm{C}$ ). The effect of the heating rate is similar in all samples, presenting a displacement to higher temperatures as the heating rate increases. This has been explained for other materials, being the kinetic law responsible for this behavior $[23,33]$.

The effect of the presence of oxygen is also different for the different materials. The first stages of the decomposition of CEM3 in the presence of oxygen coincide with those presented in inert atmosphere. Nevertheless, the oxygen appears to strongly react with the pyrolytic residue of CEM3 decomposition, producing a fast weight loss.

The presence of oxygen strongly accelerates the decomposition of ROGERS laminates, although the weight loss at time infinity is similar both in the presence and absence of oxygen, so the oxygen does not interact very much with the solid residue.

FR4 laminate presents a decomposition in air that is accelerated with respect to the pyrolysis, but it seems that the decomposition is split into two different processes, one 
centered at approx. $320^{\circ} \mathrm{C}$ and the other at $400{ }^{\circ} \mathrm{C}$. The similarity in the behavior of $\mathrm{FR} 4$ and CEM3 laminates indicates their similar composition, as mentioned before.

The total mass loss at the final temperature in the presence of air is an indicative of the ash content of the material, and correlates well with the data presented in Table 1.

\subsection{Analysis of gases evolved during the decomposition of laminates.}

During the decomposition runs in the reactor, gases were conveniently collected and analyzed. The analysis of the hydrocarbons by FID shows a very small amount of methane, nhexane, toluene and xylene. Other compounds of low molecular weight present nil emission or close to zero (ethylene, propylene, benzene, among others). Details on the measured compounds are found in Figure 2. Note that the concentration is expressed in grams of compound per volume of gas, as the analyses were performed over different small samples of the gas sampled at different times along the experimental runs. As can be seen, the emissions are centered in the first part of the experiments, being the emissions of all species very small at time higher than $20 \mathrm{~min}$. Figure 2 shows clearly that the presence of the catalyst reduces the emissions of hydrocarbons in almost all runs. Only the run performed with the ROGERS laminate does not present a clear decrease of the emissions in the presence of the iron catalyst.

TCD chromatography was used to analyze hydrogen and carbon oxides $\left(\mathrm{CO}\right.$ and $\left.\mathrm{CO}_{2}\right)$. The amount of hydrogen produced during pyrolysis is very low (in the range $0.2-0.5 \mathrm{~g} / \mathrm{m}^{3}$ ), and in most cases was not detected. The levels of carbon oxides found were in most cases near 2 $\mathrm{g} / \mathrm{m}^{3}$ for $\mathrm{CO}$ and $5 \mathrm{~g} / \mathrm{m}^{3}$ for $\mathrm{CO}_{2}$, without a clear variation along time.

During the decomposition of the laminates presented, the formation of $\mathrm{HBr}$ and $\mathrm{Br}_{2}$ is expected and is necessary to implement a system to eliminate it in a possible commercial system. Nevertheless, the formation of such pollutants has been studied before, especially from FR4 laminates [7], and does not present great difficulties to be eliminated.

\subsection{PAHs and semivolatile compounds}

The results of the emission of PAHs for the six runs (with and without catalyst) are illustrated in Figure 3; the experiments with iron-clay catalyst are marked in the Figure as 'C'. In these analyses, the whole amount of each compound is collected in the XAD-2 resin, so the emission is expressed as milligram of compound per kilogram of laminate decomposed.

In all runs, formation of PAHs was observed. In the first run of FR4 the total amount of PAHs was equal to $9950 \mathrm{mg} / \mathrm{kg}$ sample. The addition of calcined iron-clay catalyst led to a 
decrease of pollutants in $1520 \mathrm{mg} / \mathrm{kg}$. Laminate CEM3 produced around $14000 \mathrm{mg} / \mathrm{kg}$ PAHs during the decomposition, but the presence of iron increased effectively the conversion, and the total concentration dropped to $8300 \mathrm{mg} / \mathrm{kg}$ sample. The same situation was observed with ROGERS laminate, and after catalytic treatment with iron-clay granules the total concentration dropped from 11380 to $6380 \mathrm{mg} / \mathrm{kg}$.

In each run, the most abundant PAHs detected were naphthalene, acenaphthylene, phenanthrene and fluorene. These compounds are identified in class 4 tars (light polyaromatic), as defined by Devi et al. [22]. As can be seen, after thermal decomposition at $900{ }^{\circ} \mathrm{C}$, the contribution of naphthalene is more than $30 \%$ and $45 \%$, for CEM3 and ROGERS respectively, whereas the amount of naphthalene in FR4 is much lower (230 $\mathrm{mg} / \mathrm{kg}$ ). The conversion of naphthalene over calcined iron-clay catalyst reaches a $14 \%$ (CEM3-C) and $42.5 \%$ (ROGERS-C). According to Devi [22] this low conversion may be due to the fact that naphthalene is a very stable compound, or also that the decomposition of PAHs with a higher ring number leads to the formation of naphthalene.

The amount of acenaphthylene decreased by a factor of 14 in FR4-C, twice in CEM3-C. Moreover, the smaller yields of fluorene and phenanthrene after the catalytic process led to a decrease in light PAH amounts. In this way, calcined iron-clay is reactive with respect to tar decomposition. This can be explained by the steam reforming reactions in the reactor, that reduces the tar in the exiting gas [22].

Table 3 shows semivolatile compound distribution. The decomposition process resulted in high yields of semivolatile compounds in the experiments without catalyst. The highest amounts were observed for FR-4 and CEM3 samples (5680 and $5550 \mathrm{mg} / \mathrm{kg}$ respectively), in contrast to ROGERS which only emitted $3390 \mathrm{mg} / \mathrm{kg}$. The most abundant semivolatile compounds in each run were biphenyl, dibenzofuran, benzene and naphthalene derivatives, benzo[a]fluorene and benzo[c]fluorene.

As can be seen, in the presence of catalyst a great decrease is observed in the total amount of semivolatile compounds for FR4-C, CEM3-C, and a slight decrease for ROGERS-C. Semivolatile yields are $2760 \mathrm{mg} / \mathrm{kg}$ lower for FR-4, $2400 \mathrm{mg} / \mathrm{kg}$ lower for CEM3 and only $470 \mathrm{mg} / \mathrm{kg}$ lower for ROGERS. These data show that oxidative atmosphere, which was described by Ortuño et al. [7] and also catalytic cracking lead to the destruction of these compounds.

\subsection{Bromophenols and PBDD/Fs}


As commented above, specific analyses of brominated phenols and brominated dioxins and furans were performed during the eight runs performed in the laboratory reactor.

Regarding the analyses of the brominated dioxins and furans (PBDD/Fs), the recoveries obtained for the labelled standards were within the ranges established for the chlorinated analogues [34], namely, $50-130 \%$ for tetra- to hexachlorinated congeners, and $40-130 \%$ for hepta- and octachlorinated congeners.

However, any of the samples presented detectable amounts of the brominated congeners. Considering the limits of detection (based on the response of congeners of the same bromination level present in the calibration solutions), the amounts of PBDD/F congeners, if released, would be less than $5 \mathrm{pg} / \mathrm{g}$ for tetra- and penta-BDD/F congeners, $20 \mathrm{pg} / \mathrm{g}$ for hexaand hepta-BDD/Fs and $40 \mathrm{pg} / \mathrm{g}$ for OBDD/Fs.

When taking a conservative approach, and setting all nondetects to their detection limits, a total PBDD/F emission value of $210 \mathrm{pg} / \mathrm{g}$ is obtained, which corresponds to $18.6 \mathrm{pg}$ $\mathrm{WHO}_{2005}-\mathrm{TEQ} / \mathrm{g}$ in toxicity units. In order to calculate this last value, the Toxic Equivalency Factors (TEFs) for PBDD/Fs were assigned as those of their PCDD/Fs equivalents $[35,36]$. This emission factor is more than 6 times lower than the observed during combustion of waste printed circuit boards at $850{ }^{\circ} \mathrm{C}$ in a similar horizontal laboratory reactor [7], and nearly 10 times lower when comparing the toxicity of the emissions. In this sense, it seems that the presence of water at this high temperature produces the degradation of PBDD/Fs.

With respect to the emission of bromophenols, Figure 4 presents a summary with the evolution of these compounds at the different experimental conditions. The emission of total brominated phenols is quite low, in the range of $0.06-4.87 \mathrm{mg} / \mathrm{kg}$ in all runs. The more abundant congeners are mono-bromophenols (with bromine in the positions 2-, 3- and 4-), followed by di-bromophenols (2,4- and 2,6-congeners) and 2,4,6-tribromophenol. Laminate ROGERS presents a very low emission, as expected because it does not contain brominated flame retardants.

In previous studies [7], emissions of bromophenols in the pyrolysis and combustion of FR4 printed circuits in the presence and in the absence of metals were studied in our laboratory. In these runs, the emissions of bromophenols during the pyrolysis at $850{ }^{\circ} \mathrm{C}$ was $830 \mathrm{mg} / \mathrm{kg}$ sample for the non-metallic fraction, and $4.7 \mathrm{mg} / \mathrm{kg}$ when the whole sample was used. In the case of combustion runs, $0.25-0.35 \mathrm{mg} / \mathrm{kg}$ were detected, similar to those measured in the 
present work. These results point out the importance of the metals in the formation of such compounds, as well as the easy decomposition that is produced in oxidative atmosphere (both oxygen and steam). Nevertheless, the small values of bromophenols emitted are slightly increased in the presence of the iron-clay catalyst. Different authors[37] observed PCDD formation reactions on clay surfaces at much lower temperatures $\left(<200{ }^{\circ} \mathrm{C}\right)$ but these reactions could be also involved in the thermal decomposition conditions.

\section{Conclusions}

The thermal decomposition and high temperature decomposition of three types of laminates (FR4, CEM3 and ROGERS) has been studied.

The thermogravimetric study reveals important differences in the form that the oxygen acts in the polymer matrices: on the one hand, FR4 and CEM3 show a very strong interaction with oxygen, whereas the weight loss in ROGERS laminates is similar both in inert and oxygen atmosphere.

When treating the laminates with steam at $900{ }^{\circ} \mathrm{C}$, the gaseous emissions are reduced to methane, hexane, toluene and xylenes, with nil production of other hydrocarbons. It has been proved that the production of PAHs and semivolatile compounds is considerably reduced if iron-clay catalyst is used in the reactor. The emission of bromophenols is in any case very low ( $<5 \mathrm{mg} / \mathrm{kg}$ sample), and can be somewhat affected by the presence of iron-clay, but no important differences were found. The emission of PBDD/Fs is in all runs well below 200 $\mathrm{pg} / \mathrm{g}$. In general, the emission of brominated compounds is much lower in the thermal decomposition of ROGERS, compared to FR4 and CEM3.

\section{Aknowledgements}

Support for this work was provided by the CTQ2016-76608-R project from the Ministry of Economy and Competitiveness (Spain) and the PROMETEOII/2014/007 project from the Valencian Community Government (Spain). 


\section{References}

350 [1] Y. Yang, R. Boom, B. Irion, D.J. van Heerden, P. Kuiper and H. de Wit, Chemical Engineering and Processing: Process Intensification, 51, (2012) 53.

[2] M. Xing and F.S. Zhang, Chemical Engineering Journal, 219, (2013) 131.

353 [3] J. Michalski, in Wydawnictwa NaukowoTechniczne, 1992, p. 30.

354 [4] R. Cayumil, R. Khanna, M. Ikram-Ul-Haq, R. Rajarao, A. Hill and V. Sahajwalla, Waste Management, 34, (2014) 1783.

[5] J. Cui and L. Zhang, Journal of Hazardous materials, 158, (2008) 228.

357 [6] M. Zabłocka-Malicka, P. Rutkowski and W. Szczepaniak, Waste Management, 46, (2015) 488.

358 [7] N. Ortuño, J.A. Conesa, J. Moltó and R. Font, Science of the Total Environment, 499, (2014) 27.

[8] M. Ni, H. Xiao, Y. Chi, J. Yan, A. Buekens, Y. Jin and S. Lu, Waste Management, 32, (2012) 568.

[9] H. Xiao, Y. Chi and A. Buekens, Environmental Progress and Sustainable Energy, 33, (2014) 1105.

[10] C. Quan, A. Li, N. Gao and Z. dan, Journal of Analytical and Applied Pyrolysis, 89, (2010) 102.

[11] I. de Marco, B.M. Caballero, M.J. Chomón, M.F. Laresgoiti, A. Torres, G. Fernández and S. Arnaiz, Journal of Analytical and Applied Pyrolysis, 82, (2008) 179.

[12] Q. Guo, X. Yue, M. Wang and Y. Liu, Powder Technology, 198, (2010) 422.

[13] W.J. Hall and P.T. Williams, Circuit World, 33, (2007) 43.

[14] C. Vasile, M.A. Brebu, M. Totolin, J. Yanik, T. Karayildirim and H. Darie, Energy and Fuels, 22, (2008) 1658.

[15] J. Guan, J. Wang, X. Min and W. Wu, Procedia Environmental Sciences, 16, (2012) 461.

[16] N.M. Tue, S. Takahashi, A. Subramanian, S. Sakai and S. Tanabe, Environmental Science: Processes \& Impacts, 15, (2013) 1326.

[17] H. Duan, J. Li, Y. Liu, N. Yamazaki and W. Jiang, Environmental Pollution, 161, (2012) 185.

[18] A. Smoliński, N. Howaniec and K. Stańczyk, Renewable Energy, 36, (2011) 1836.

[19] J.F. González, S. Román, D. Bragado and M. Calderón, Fuel Processing Technology, 89, (2008) 764.

[20] T. Kimura, T. Miyazawa, J. Nishikawa, S. Kado, K. Okumura, T. Miyao, S. Naito, K. Kunimori and K. Tomishige, Applied Catalysis B: Environmental, 68, (2006) 160.

[21] S. Rapagnà, M. Virginie, K. Gallucci, C. Courson, M. Di Marcello, A. Kiennemann and P.U. Foscolo, Catalysis Today, 176, (2011) 163.

[22] L. Devi, K.J. Ptasinski, F.J.J.G. Janssen, S.V.B. Van Paasen, P.C.A. Bergman and J.H.A. Kiel, Renewable Energy, 30, (2005) 565.

[23] J.A. Conesa and A. Domene, Journal of Analytical and Applied Pyrolysis, 113, (2015) 680.

[24] J.F. González, S. Román, G. Engo, J.M. Encinar and G. Martínez, Biomass and Bioenergy, 35, (2011) 4324.

[25] M. Zablocka-Malicka, W. Szczepaniak, A. Zielinska and P. Rutkowski, Ecological Chemistry and Engineering, 23, (2014) 33.

[26] P. Monka, W. Szczepaniak and M. Zablocka-Malicka, Technical Transactions, 108, (2011) 119.

[27] J.A. Salbidegoitia, E.G. Fuentes-Ordóñez, M.P. González-Marcos, J.R. González-Velasco, T. Bhaskar and T. Kamo, Fuel Processing Technology, 133, (2015) 69.

[28] US EPA, in US EPA (Ed.), SW-846, United States Environmental Protection Agency, Office of Solid Waste, Washington, D.C., 1994.

[29] Y. Miao, J. Xue, F. Xia, X. Yin and C. Wu, Biomass and Bioenergy, 34, (2010) 1855.

[30] I. Aracil, R. Font and J.A. Conesa, Journal of Analytical and Applied Pyrolysis, 74, (2005) 465.

[31] US EPA, in US EPA (Ed.), SW-846, United States Environmental Protection Agency, Office of Solid Waste, Washington, D.C., 2007.

[32] B. Wyrzykowska, D. Tabor and B.K. Gullett, Analytical Chemistry, 81, (2009) 4334. 
[33] J. Molto, R. Font, J.A. Conesa and I. Martin-Gullon, Journal of Analytical and Applied Pyrolysis, 76, (2006) 124.

400

[34] ECS, in ECS (Ed.), European Committee for Standardization, Brussels, 2006.

401

[35] M. van den Berg, L.S. Birnbaum, M. Denison, M. De Vito, W. Farland, M. Feeley, H. Fiedler, H. Hakansson, A. Hanberg, L. Haws, M. Rose, S. Safe, D. Schrenk, C. Tohyama, A. Tritscher, J. Tuomisto, M. Tysklind, N. Walker and R.E. Peterson, Toxicological Sciences, 93, (2006) 223.

405

406

407

408

[36] M. van den Berg, M.S. Denison, L.S. Birnbaum, M. DeVito, H. Fiedler, J. Falandysz, M. Rose, D. Schrenk, S. Safe, C. Tohyama, A. Tritscher, M. Tysklind and R.E. Peterson, Toxicological Sciences, (2013).

[37] C. Gu, C. Liu, Y. Ding, H. Li, B.J. Teppen, C.T. Johnston and S.A. Boyd, Environmental Science and Technology, 45, (2011) 3445.

409

410

411 
414 Table 1. Ultimate analysis of each type of laminate.

415 Table 2. X-ray fluorescence analysis of the laminates used in the present work.

416 Table 3. Distribution of semivolatiles during thermal decomposition.

417 Figure 1. Characterization of the decomposition of the laminates in pyrolytic (nitrogen) and 418 oxidative atmosphere (air). Thermogravimetric plots: mass fraction vs. temperature at the 419 different heating rates.

420 Figure 2. Distribution of light hydrocarbons during thermal decomposition process without 421 and with catalyst, measured in gas chromatography by FID detector.

422 Figure 3. Emission of PAHs during thermal decomposition of the different laminates without 423 and with catalyst ("C" refers to the presence of catalyst).

424 Figure 4. Emission of bromophenols during thermal decomposition of the different laminates 425 without and with catalyst ("C" $\mathrm{C}$ " refers to the presence of catalyst). 
427 Table 1. Ultimate analysis of each type of laminate.

428

\begin{tabular}{lccc}
\hline wt\% & FR4 & CEM3 & ROGERS4003 \\
\hline $\mathrm{C}$ & 24.5 & 25.1 & 12.6 \\
$\mathrm{H}$ & 2.1 & 3.1 & 1.4 \\
$\mathrm{~N}$ & 0.6 & 1.1 & $\mathrm{nd}$ \\
$\mathrm{S}$ & $\mathrm{nd}$ & $\mathrm{nd}$ & $\mathrm{nd}$ \\
$\mathrm{O}$ and ash (by difference) & 72.8 & 70.7 & 86.0 \\
HHV (MJ/kg) & 10.48 & 9.68 & 5.94 \\
\hline
\end{tabular}

429

nd: not detected

430

431 
432 Table 2. X-ray fluorescence analysis of the laminates used in the present work.

\begin{tabular}{lccc}
\hline wt\% & FR4 & CEM3 & ROGERS4003 \\
\hline $\mathrm{Si}$ & 16.26 & 13.52 & 30.30 \\
$\mathrm{Ca}$ & 9.81 & 4.00 & 3.28 \\
$\mathrm{Cu}$ & 5.87 & 3.81 & 10.24 \\
$\mathrm{Al}$ & 4.31 & 12.00 & 1.57 \\
$\mathrm{Mg}$ & 1.00 & 2.14 & 0.09 \\
$\mathrm{Ti}$ & 0.28 & 0.21 & 0.07 \\
$\mathrm{Fe}$ & 0.26 & 0.28 & 0.24 \\
$\mathrm{~K}$ & 0.17 & 0.09 & 0.02 \\
$\mathrm{Na}$ & 0.14 & 0.09 & nd \\
$\mathrm{As}$ & 0.09 & nd & nd \\
$\mathrm{P}$ & 0.08 & 0.10 & 0.02 \\
$\mathrm{Ba}$ & 0.06 & nd & nd \\
$\mathrm{Sr}$ & 0.04 & 0.04 & 0.02 \\
$\mathrm{Zn}$ & 0.02 & 0.01 & 0.05 \\
$\mathrm{Zr}$ & 0.02 & 0.01 & 0.004 \\
$\mathrm{~W}$ & nd & nd & nd \\
$\mathrm{Ce}$ & nd & nd & nd \\
$\mathrm{Cr}$ & nd & nd & 0.02 \\
\hline
\end{tabular}




\begin{tabular}{|c|c|c|c|c|c|c|}
\hline \multirow{2}{*}{ Compound } & FR4 & FR4 C & CEM3 & CEM3 C & ROGERS & ROGERS C \\
\hline & \multicolumn{6}{|c|}{$\mathrm{mg}$ compound/kg sample (ppm) } \\
\hline 2-pentanone, 4-hydroxy-4-methyl- & 90 & 180 & 220 & 380 & 10 & 140 \\
\hline benzofuran & - & - & 70 & - & - & - \\
\hline benzene, 1-propynyl- & - & - & 140 & 130 & 160 & 290 \\
\hline benzofuran, 7-methyl- & - & - & 20 & 20 & - & - \\
\hline benzofuran, 2-methyl- & - & - & 50 & 50 & - & - \\
\hline benzene, 1,3-diethenyl- & - & - & - & - & 20 & - \\
\hline benzene, 1,4-diethenyl- & - & - & - & - & 20 & - \\
\hline indene, 3-methyl- & - & - & - & - & 30 & - \\
\hline naphthalene, 1,2-dihydro- & - & - & - & - & 20 & - \\
\hline 1-methylene-1H-indene & - & - & - & - & 30 & - \\
\hline 1,4-dihydronaphthalene & - & - & - & - & 10 & - \\
\hline naphthalene, 1-methyl- & 60 & 90 & 280 & 150 & 190 & 470 \\
\hline naphthalene, 2-methyl- & 100 & 70 & 280 & 150 & 100 & 290 \\
\hline biphenyl & 470 & 640 & 530 & 410 & 550 & 330 \\
\hline 1,1'-biphenyl, 2-methyl- & - & - & - & - & 20 & 10 \\
\hline naphthalene, 2,6-dimethyl- & 10 & - & 10 & - & 30 & 30 \\
\hline naphthalene, 1,7-dimethyl- & 10 & - & 10 & - & 20 & 20 \\
\hline naphthalene, 2-ethenyl- & 80 & - & - & 30 & - & - \\
\hline 1,1'-biphenyl, 3-methyl- & 80 & 30 & 60 & 40 & 50 & 40 \\
\hline 1-isopropenylnaphthalene & 40 & 50 & 50 & 40 & 40 & 20 \\
\hline 1,1'-biphenyl, 4-methyl- & 50 & 10 & 30 & 20 & 30 & 20 \\
\hline 2-naphthalenecarbonitrile & 60 & 30 & 90 & 50 & - & - \\
\hline 2-naphthalenamine & 30 & - & 20 & 10 & - & - \\
\hline dibenzofuran & 250 & 340 & 310 & 230 & 10 & 30 \\
\hline 9H-fluorene, 9-methyl- & 90 & 20 & 50 & - & 100 & 70 \\
\hline phenalene & 90 & - & 70 & - & 40 & 30 \\
\hline 2-hydroxyfluorene & 50 & - & 40 & 40 & 100 & - \\
\hline phenanthrene, 9,10-dihydro- & - & - & - & - & 10 & 140 \\
\hline 9H-fluorene, 1-methyl- & 50 & - & - & - & 40 & 50 \\
\hline 1,2-diphenylethylene & - & - & - & - & 90 & - \\
\hline 9H-fluorene, 2-methyl- & 20 & - & 50 & 20 & 10 & - \\
\hline 9H-fluoren-9-one, hydrazone & 110 & - & 30 & - & - & - \\
\hline phenanthridine & 50 & - & 60 & - & - & - \\
\hline naphthalene, 1-phenyl- & 180 & - & 110 & 60 & 200 & 80 \\
\hline phenanthrene, 1-methyl- & 70 & 20 & 60 & 30 & 60 & 40 \\
\hline phenanthrene, 2-methyl- & 90 & 30 & 90 & 40 & 80 & 50 \\
\hline benzo[def]fluorene & 310 & 40 & 270 & 100 & 190 & 100 \\
\hline phenanthrene, 3-methyl- & 100 & 20 & 70 & 30 & 60 & 40 \\
\hline 2-phenylnaphthalene & 400 & 330 & 260 & 160 & 320 & 170 \\
\hline benzo[a]fluorene & 440 & - & 340 & 140 & 140 & 90 \\
\hline triphenylene & 50 & 50 & 40 & 20 & 30 & 20 \\
\hline
\end{tabular}




\begin{tabular}{l|cc|cc|cc} 
benzo[c]fluorene & 380 & 10 & 310 & 120 & 160 & 60 \\
pyrene, 1-methyl- & 70 & - & 80 & 20 & 110 & 10 \\
benzo[c]phenanthrene & 330 & 360 & 280 & 150 & 100 & 60 \\
11H-benzo[a]fluoren-11-one & 170 & 180 & 140 & 30 & - & 130 \\
chrysene, 2-methyl- & 90 & 10 & 80 & 10 & 50 & - \\
phenanthrene, 2-phenyl- & 130 & 130 & 100 & 10 & 130 & - \\
9-phenylanthracene & 100 & 40 & 70 & 30 & 30 & 10 \\
13H-dibenzo[a,h]fluorene & 120 & - & 110 & - & - & - \\
11H-indeno[2,1-a]phenanthrene & 200 & - & 150 & - & - & - \\
pyrene, 1-phenyl- & 130 & 20 & 80 & 30 & - & - \\
benzo(a)chrysene & 90 & 10 & 60 & 30 & - & - \\
benzo[b]triphenylene & 180 & 100 & 120 & 50 & - & - \\
dibenzo(a,e)fluoranthene & 130 & 70 & 140 & 50 & - & - \\
dibenzo[a,e]pyrene & 130 & 40 & 120 & 30 & - & - \\
\hline Total & 5680 & 2920 & 5550 & 3150 & 3390 & 2920 \\
\hline
\end{tabular}

436

437 


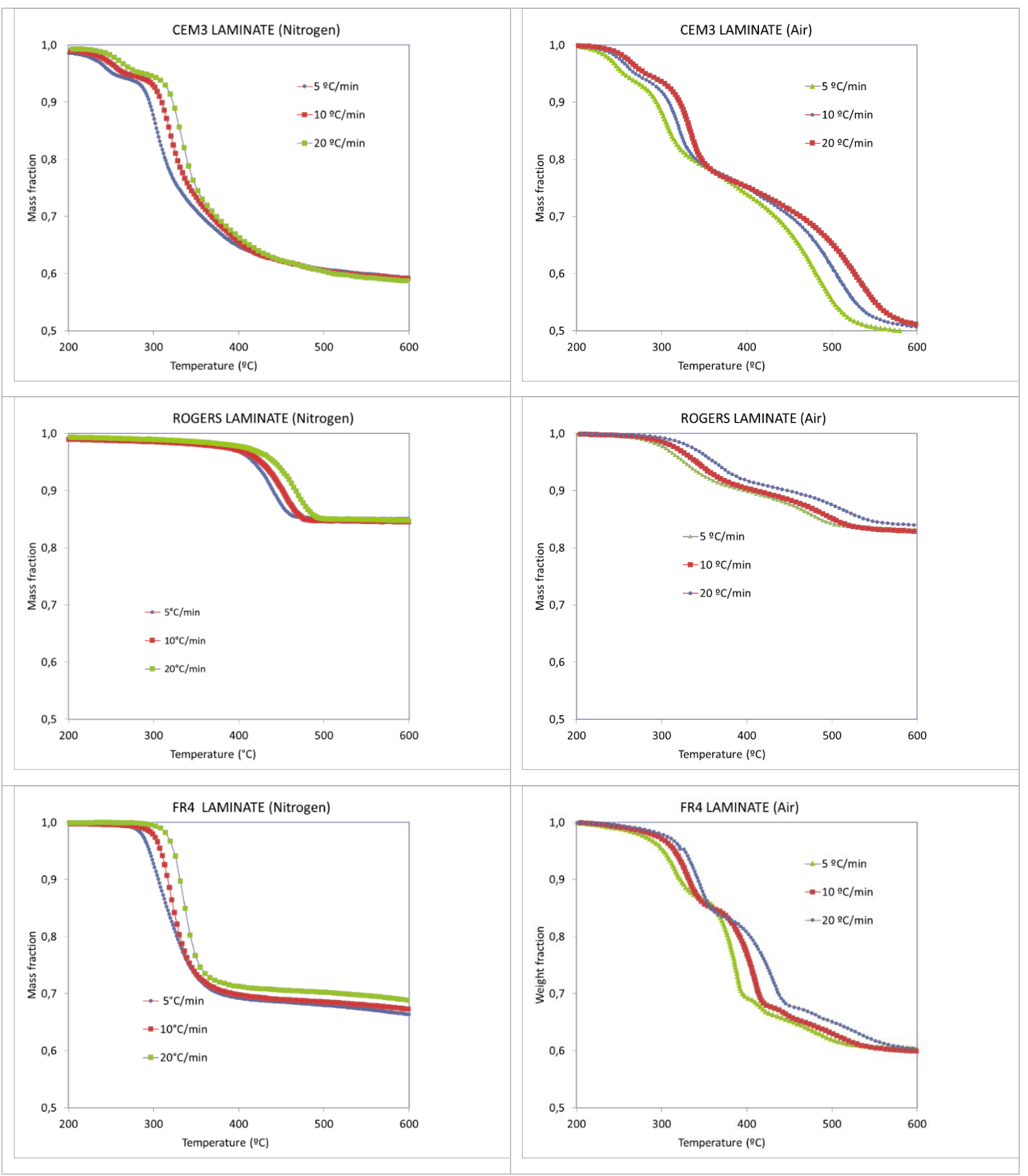

439

440 Figure 1. Characterization of the decomposition of the laminates in pyrolytic (nitrogen) and

441 oxidative atmosphere (air). Thermogravimetric plots: mass fraction vs. temperature at the 442 different heating rates. 

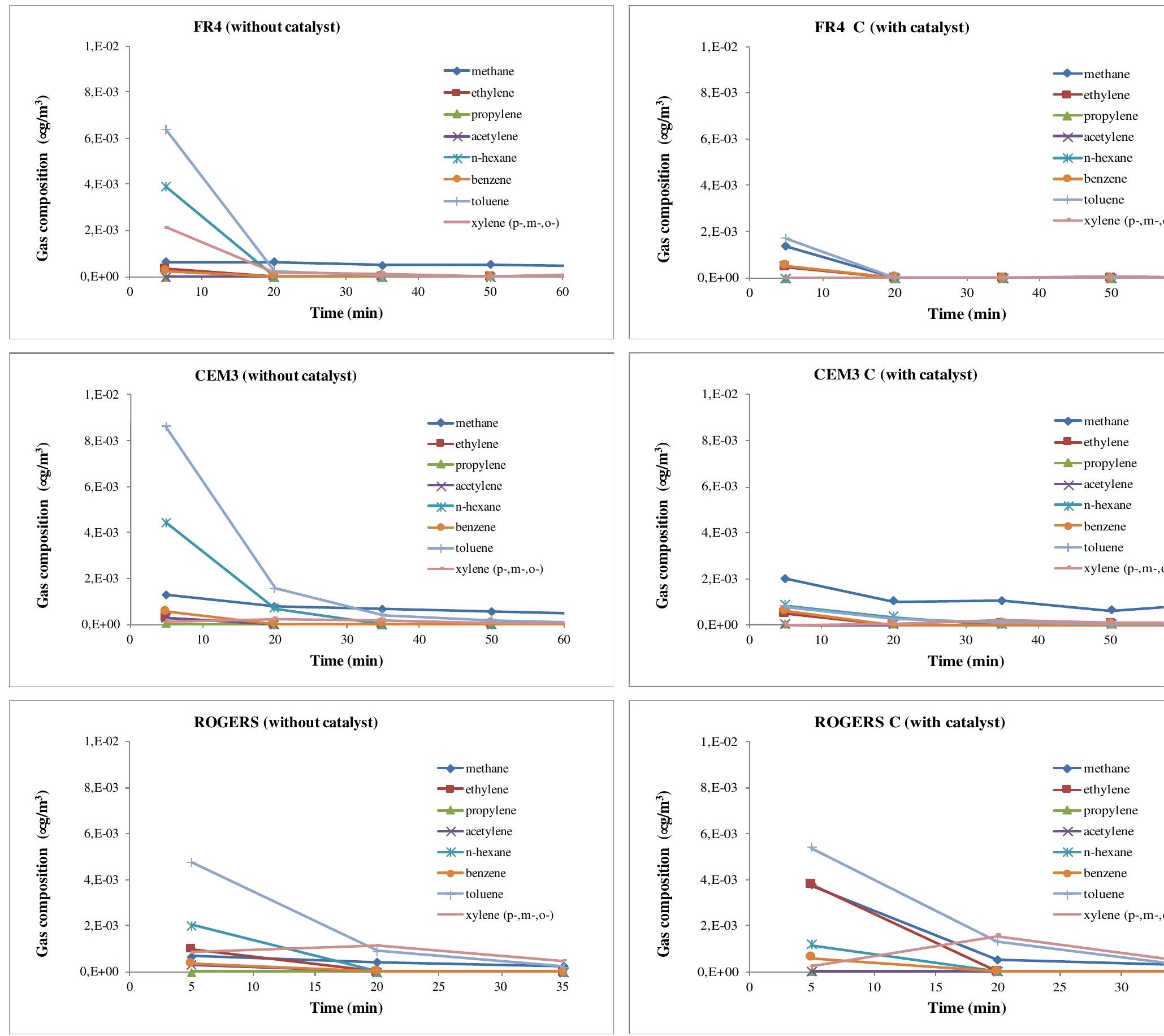

447 Figure 2. Distribution of light hydrocarbons during thermal decomposition process without

448 and with catalyst, measured in gas chromatography by FID detector. 
GASIFICATION OF LAMINATES WITH AND WITHOUT CATALYST

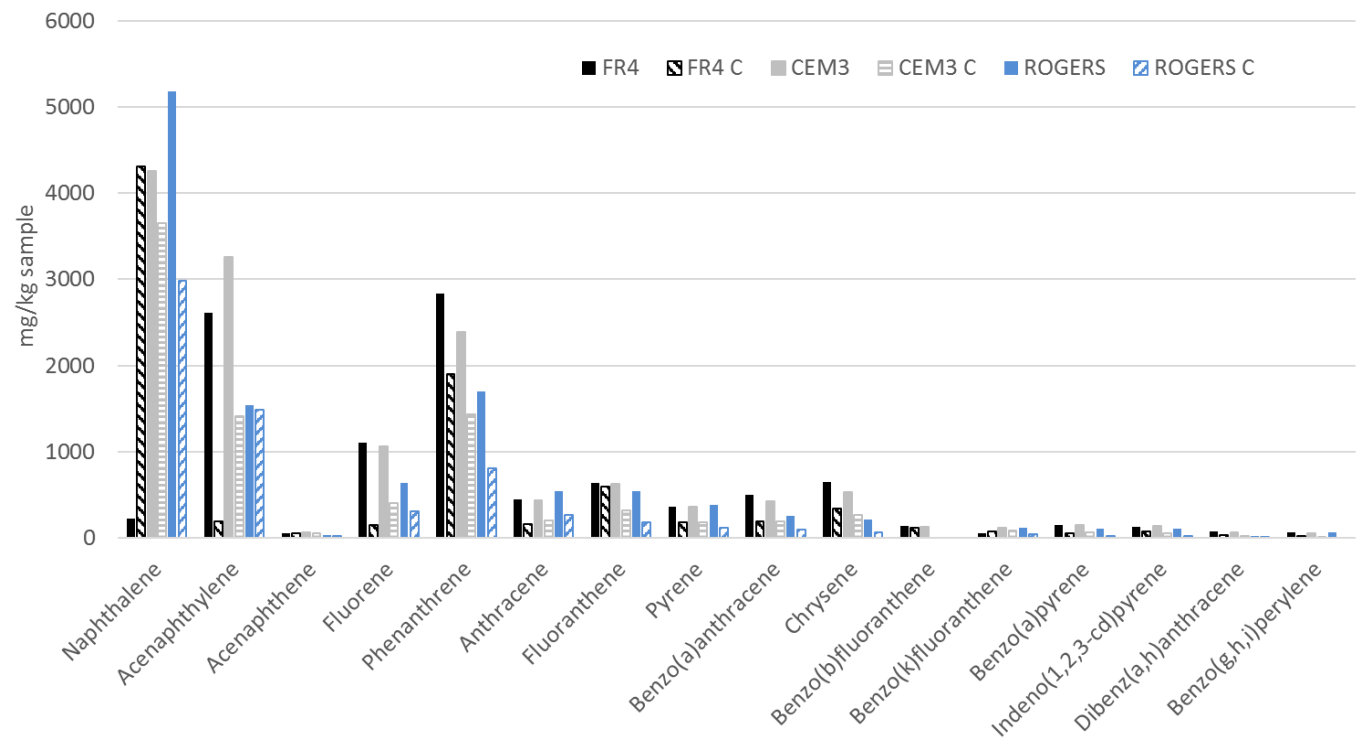

452 Figure 3. Emission of PAHs during thermal decomposition of the different laminates without 453 and with catalyst ("C" refers to the presence of catalyst). 
GASIFICATION OF LAMINATES WITH AND WITHOUT CATALYST

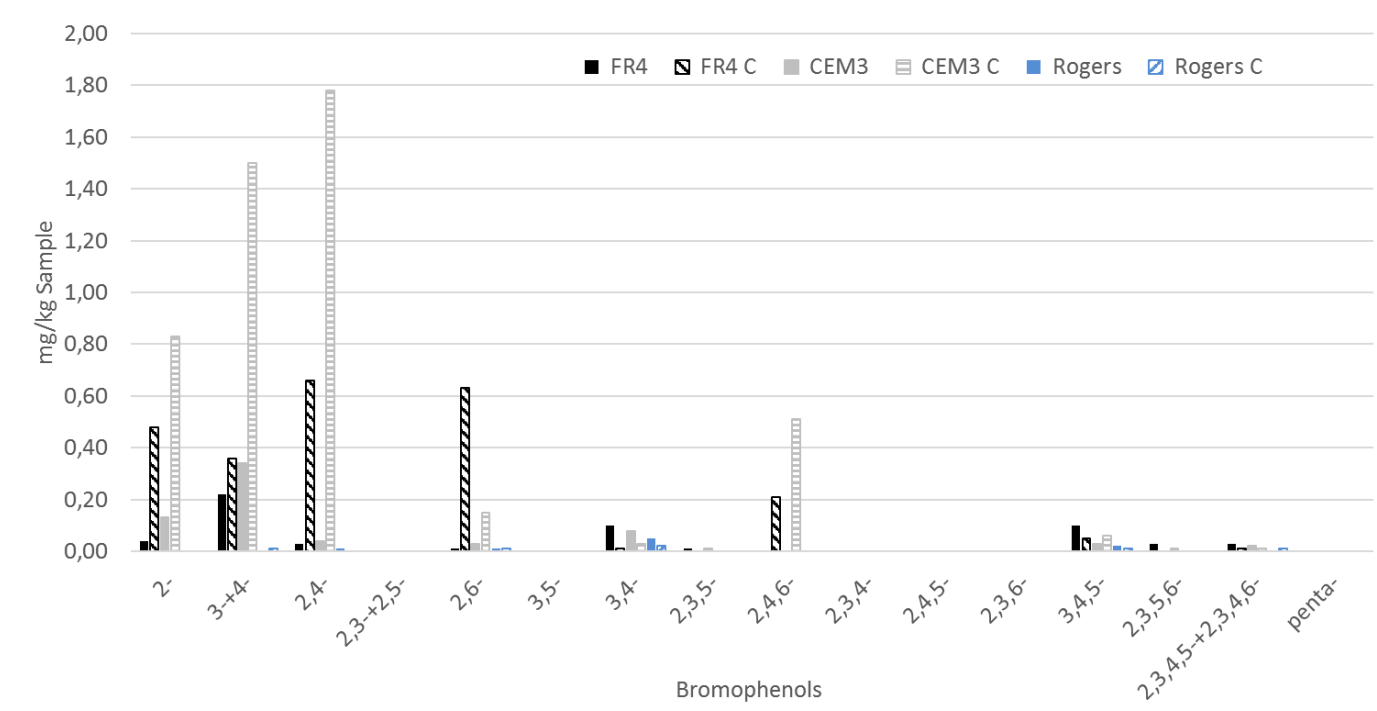

456

457 Figure 4. Emission of bromophenols during thermal decomposition of the different laminates 458 without and with catalyst ("C $\mathrm{C}$ " refers to the presence of catalyst).

459 